\title{
Effect of Smashing Ridge Tillage Depth on Soil Water, Salinity, and Yield in Saline Cotton Fields in South Xinjiang, China
}

\author{
Zhentao Bai ${ }^{1,2}$, Hongguang Liu ${ }^{1,2, *}$, Tangang Wang ${ }^{3, *}$, Ping Gong ${ }^{1,2}$, Huiqin $\operatorname{Li}^{3}$, Ling Li ${ }^{1,2}$, Bao Xue ${ }^{1,2}$, \\ Minghai Cao ${ }^{1,2}$, Jinping Feng ${ }^{1,2} \mathbb{C}$ and Yibin $\mathrm{Xu}^{1,2}$ \\ 1 College of Water Conservancy \& Architectural Engineering, Shihezi University, Shihezi 832000, China; \\ baizt2020@163.com (Z.B.); gongping0993@163.com (P.G.); liling2021edn@163.com (L.L.); \\ a6856985@163.com (B.X.); caominghai147@163.com (M.C.); feng2468787347@163.com (J.F.); \\ 18794876724@163.com (Y.X.) \\ 2 Xinjiang Production \& Construction Group Key Laboratory of Modern Water-Saving Irrigation, \\ Shihezi 832000, China \\ 3 Institute of Agricultural Science of the Third Division of Xinjiang Production and Construction Corps, \\ Tumushuk 843900, China; qinqindeshijie@163.com \\ * Correspondence: liuhongguang-521@163.com (H.L.); wtg731@163.com (T.W.)
}

Citation: Bai, Z.; Liu, H.; Wang, T.; Gong, P.; Li, H.; Li, L.; Xue, B.; Cao, M.; Feng, J.; Xu, Y. Effect of Smashing Ridge Tillage Depth on Soil Water, Salinity, and Yield in Saline Cotton Fields in South Xinjiang, China. Water 2021, 13, 3592. https://doi.org/ 10.3390/w13243592

Academic Editor: Jan Wesseling

Received: 11 October 2021

Accepted: 12 December 2021

Published: 14 December 2021

Publisher's Note: MDPI stays neutral with regard to jurisdictional claims in published maps and institutional affiliations.

Copyright: (c) 2021 by the authors. Licensee MDPI, Basel, Switzerland. This article is an open access article distributed under the terms and conditions of the Creative Commons Attribution (CC BY) license (https:// creativecommons.org/licenses/by/ $4.0 /)$.

\begin{abstract}
To explore the potential of smashing ridge tillage irrigation, it is necessary to investigate how smashing ridge tillage technology with mulched drip irrigation affects soil water, salinity, and cotton yield in saline fields. We conducted a two-year (2020-2021) field experiment to study the effects of different smashing ridge tillage depths on soil bulk density, moisture, salinity, dry matter production, yield, and its constituents (effective bolls, 100-bell weight). There were three smashing ridge tillage depths: A $(20 \mathrm{~cm}), B(40 \mathrm{~cm})$, and $C(60 \mathrm{~cm})$, with traditional tillage as the $C T$. The results showed that all of the smashing ridge tillage could reduce soil bulk density, improve the utilization and uptake of deep soil water during the rapid growth period, and reduce the soil salt content. Compared with the CT treatment, the average soil bulk density of the 0-60 cm soil layer in treatments A, B, and C in 2020 and 2021 decreased by 3.05\%, 5.87\%, 10.09\%, and $1.65 \%, 4.48 \%$, and $8.49 \%$, respectively. The average soil water content in the $0-120 \mathrm{~cm}$ soil layer at the flowering and boll stage decreased by $3.68 \%, 6.28 \%, 9.04 \%$, and $3.59 \%, 6.52 \%$, and $9.98 \%$, respectively; the soil salt content in the $0-120 \mathrm{~cm}$ soil layer at the boll opening stage decreased by $4.21 \%, 6.75 \%, 11.95 \%$, and $5.47 \%, 24.25 \%$, and $54.13 \%$, respectively. Cotton dry matter production and yield tended to increase with an increasing depth of smash ridge tillage. Treatment $\mathrm{C}$ obtained the maximum dry matter production, seed cotton yield, effective bolls, and 100-boll weight. The dry matter production at the boll opening stage was significantly increased by $17.16 \%$ and $15.91 \%$, and the yield was significantly increased by $65.24 \%$ and $84.14 \%$ in treatments C in 2020 and 2021, respectively, compared to CT. The smashing ridge tillage of $60 \mathrm{~cm}$ can optimize the structure of the soil tillage layer and also reduce soil salinity and increase yield, which is the suitable depth of smashing ridge tillage for saline cotton fields in the south of Xinjiang. The findings of the study can provide some theoretical basis and practical experience for the improvement of saline soils and sustainable agricultural development in South Xinjiang, China.
\end{abstract}

Keywords: smashing ridge tillage; mulched drip irrigation; soil moisture; soil salinity; yield

\section{Introduction}

Xinjiang is located in the hinterland of Northwest China and has a typical continental arid climate [1]. The region is conducive to cotton growth, and the growing conditions are favorable for cotton dry matter accumulation and fiber growth. Xinjiang is China's cotton production base, with the largest planting area and the best quality [2], and its cotton output and area account for $84.90 \%$ and $67.08 \%$ of national cotton output and area, respectively [3,4], having a significant impact on local economic and social development. 
The climate of Southern Xinjiang is extremely dry with little rain (the average annual precipitation is only $46.7 \mathrm{~mm}$ ), and water evaporative demand is large. It is an oasis ecology and irrigated agriculture. Its irrigation demand index is over $85 \%$ [5], and farmland water resources are seriously lacking. At the same time, Xinjiang has the largest saline soil area in China. The area of salinized arable land accounts for $37.72 \%$ of the total arable land area in Xinjiang, and the percentage in Southern Xinjiang reaches 49.6\% [6]. Land salinization has become a major limiting condition and limiting factor for agricultural expansion and sustainable development in Southern Xinjiang [7].

Since the introduction of drip irrigation with mulch technology to cotton cultivation in 1998, the problem of water shortages in Xinjiang has been alleviated to a certain extent. However, mulched drip irrigation technology cannot achieve the effect of salt drainage and salt washing on salinized farmland. The average annual salt accumulation in the root soil layer of the crop reached $0.36 \mathrm{~g} \mathrm{~kg}^{-1}$, and salt accumulated continuously in the field soil layer $[8,9]$. Moreover, due to the long-term implementation of continuous mechanical tillage and continuous cotton cultivation, the tillage layer of cotton fields has become shallow (the average depth of the tillage layer in the irrigated cotton areas of South Xinjiang is only $20 \mathrm{~cm}$ ) [10]. This causes the soil to harden, resulting in a poor air permeability and the formation of an impermeable plough bottom. As a result, irrigation water cannot leach salt into the deep layer, which seriously affects the effect of drainage and salt washing and severely restricts crop growth and development as well as high yield [11]. How to eliminate soil barriers in continuous cotton fields, improve the efficient use of limited irrigation water, achieve water conservation in cotton fields, efficient water use and saline land improvement synergy, and increase production and efficiency have become the key scientific issues in the current agricultural production in South Xinjiang.

Improving soil tillage practices is one of the most effective ways to improve soil structure and enhance soil quality $[12,13]$. Compared to conventional tillage, deep tillage of more than $30 \mathrm{~cm}$ can destroy hardpans and decrease soil bulk density [14], increasing soil porosity [15]. Moreover, deep tillage of compacted soil could also enhance soil health and plant disease resistance [16], as well as increase organic matter storage in agricultural soils [17]. In recent years, Wei Benhui, a researcher at the Institute of Economic Crops, Guangxi Academy of Agricultural Sciences, proposed a new tillage method called "smashing ridge tillage" in which the soil is rapidly ground by spiral bits and suspended naturally into ridges without disturbing the soil layer $[18,19]$. This tillage method can break the hard plowed bottom layer, significantly deepen the soil tillage layer, reduce the soil bulk of the tillage layer, increase soil porosity and permeability, improve soil temperature, and enhance soil nutrient content and soil water storage capacity [20-22]. Smashing ridge tillage overcomes the problems of soil consolidation and fertility reduction caused by traditional tillage that cannot be deeply tilled and loosened, shallow tillage layer, and long-term mechanical crushing [23].

Smashing ridge tillage changes the physical structure of the soil and influences the degree of soil salinization by regulating water transport. Sun et al., found that, compared with conventional tillage, interval smashing ridge tillage and continuous smashing ridge tillage reduced soil bulk density and salinity in the tillage layer and significantly increased soil water content and cotton yield [24]. Hasigerile et al., noted that smashing ridge tillage combined with desulfurized gypsum and biochar significantly reduced soil salinity and facilitated crop growth and yield improvement [25]. Smashing ridge tillage can significantly improve the yield and quality of a variety of crops such as maize, peanut, and rice, with a $10-30 \%$ increase in yield and a $5 \%$ improvement in quality [22,26-28]. The yield of winter wheat still increased by $4.55 \%$ in the sixth year after smashing ridge tillage [29]. Some other scholars have shown that under wheat and maize crop rotation conditions, smashing ridge tillage was followed by a significant contribution not only to wheat season yield but also to high maize yield in the following season [30]. It can be seen that the smashing ridge tillage led to a continuous improvement in the growing environment of the crop. 
Most of the previous studies on smashing ridge tillage technology were comparative analyses of different tillage methods in terms of soil quality, crop growth and development, and yield. However, the relationship between the depth of the smashing ridge tillage on the water and salt environment of cotton fields and crop production under the soil environment conditions of water shortage and heavy reliance on irrigation in Southern Xinjiang is not sufficiently studied, and the mechanism affecting the water and soil environment and yield of cotton fields is not clear. The lack of specifications for the depth of the work of smashing ridge tillage in response to the soil zone and obstacle factors has limited the application of smashing ridge tillage technology to local conditions. Therefore, this study investigated the effects of the depth of smashing ridge tillage on soil bulk density, water and salt content, and cotton growth and yield through two-year field experiments with drip irrigation in mulch cotton fields in South Xinjiang, revealing the mechanism of smashing ridge tillage to reduce salt and increase yield. The aim was to construct a suitable tillage structure and provide some theoretical basis and practical experience for the reasonable application of smashing ridge tillage technology in the irrigated cotton areas of South Xinjiang.

\section{Materials and Methods}

\subsection{Experimental Site Condition}

This experiment was carried out in a typical saline cotton field $\left(79^{\circ} 2^{\prime} 5^{\prime \prime} \mathrm{E}, 40^{\circ} 0^{\prime} 10^{\prime \prime} \mathrm{N}\right.$; $1098 \mathrm{~m}$ above sea level) in Tumushuk, Xinjiang, China, over two consecutive cotton growing seasons (April to October) in 2020 and 2021. The experimental site is located in a temperate extremely arid desert climate, with an average annual temperature of $15.16^{\circ} \mathrm{C}$, annual precipitation of $80.15 \mathrm{~mm}$ (Figure 1), annual evaporation of 1643-2202 $\mathrm{mm}$, and an average annual frost-free period of 225 days. The groundwater level in the test site was below $7.2 \mathrm{~m}$ in both 2020 and 2021 cotton growing seasons. The $0-120 \mathrm{~cm}$ soil layer was sandy loam, with a soil bulk density of $1.38 \mathrm{~g} \cdot \mathrm{cm}^{-3}$, field water holding capacity of $22.37 \%$, and soil electrical conductivity (EC, $\mathrm{mS} \mathrm{cm}^{-1}$ ) value of $5.19 \mathrm{mS} \mathrm{cm}^{-1}$ (soil/water weight ratio of 1:5). The contents of nitrate nitrogen, ammonium nitrogen, available phosphorus, and available potassium in soil were $52.34,3.30,7.33$, and $130.50 \mathrm{mg} \mathrm{kg}^{-1}$, respectively.
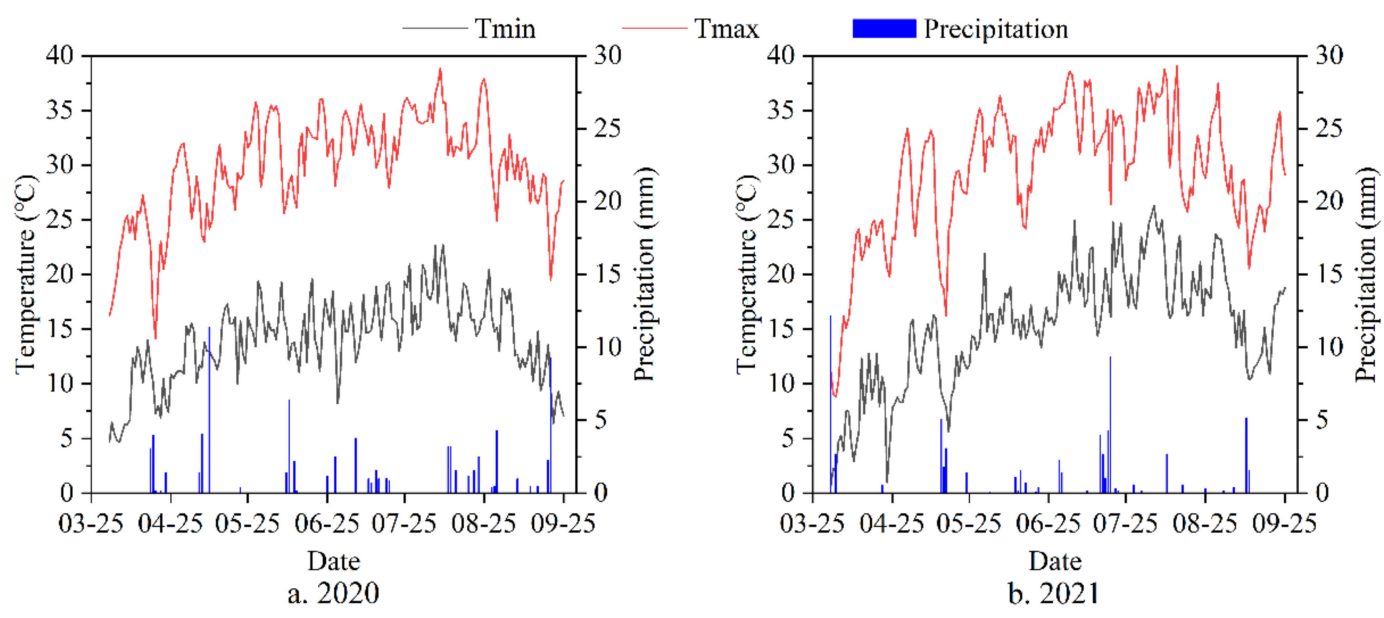

Figure 1. Distribution of precipitation and temperature during cotton growth period of experiment station in (a) 2020 and (b) 2021 .

\subsection{Experimental Design and Treatments}

This study was conducted in 12 experimental plots $(40 \times 30 \mathrm{~m}$ each). The adjacent plots were separated by $10 \mathrm{~m}$ to eliminate soil moisture and salt lateral infiltration (Figure 2a). Four treatments, with three replicates each, were arranged in 12 plots. All treatments included drip irrigation under mulch with different smashing ridge tillage depths $(\mathrm{A}, 20 \mathrm{~cm}$; $\mathrm{B}, 40 \mathrm{~cm}$; C, $60 \mathrm{~cm}$; and conventional tillage, CT). In spring 2020, the CT treatment was plowed and tilled $(20-25 \mathrm{~cm})$ using a traditional five-share plow. Treatments $\mathrm{A}, \mathrm{B}$, and C 
were operated with a Wufeng 1SGL-200 deep loosening machine (Figure 3). Large water irrigation $(270 \mathrm{~mm})$ was followed by rototilling $(15-20 \mathrm{~cm})$ and then seeding. The farming methods of all treatments in the spring of 2021 were the same as those of the CT treatment in 2020 .

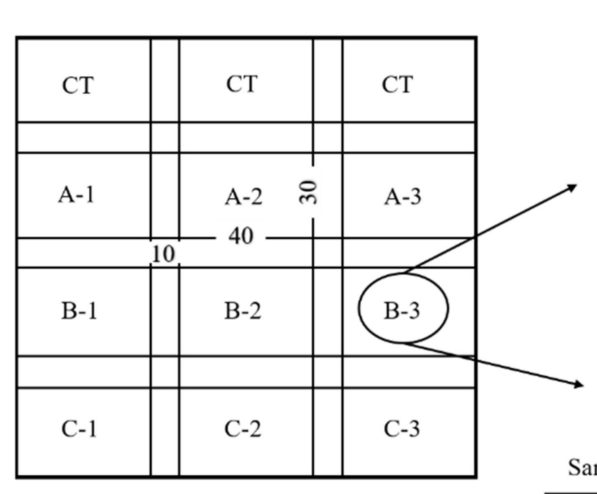

(a)

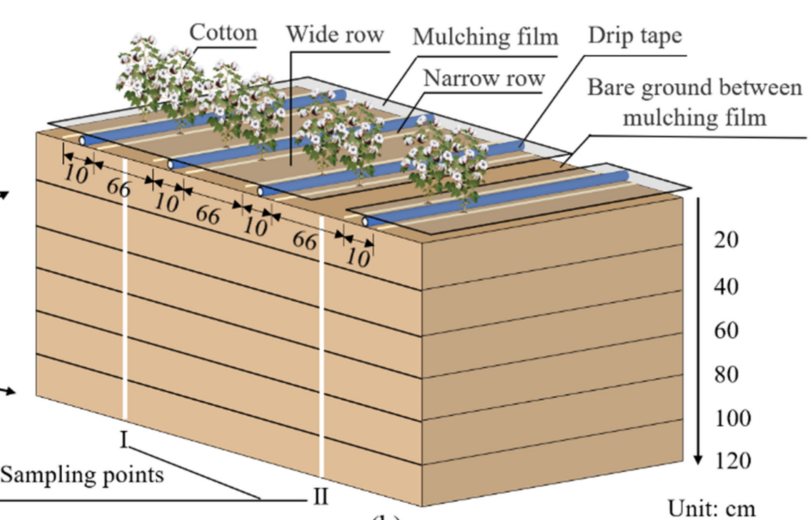

(b)

Figure 2. (a) The layout of the experimental plots and (b) a vertical section of the experimental plots. CT, conventional tillage; A, $20 \mathrm{~cm}$ B, $40 \mathrm{~cm}$ C, $60 \mathrm{~cm}$.

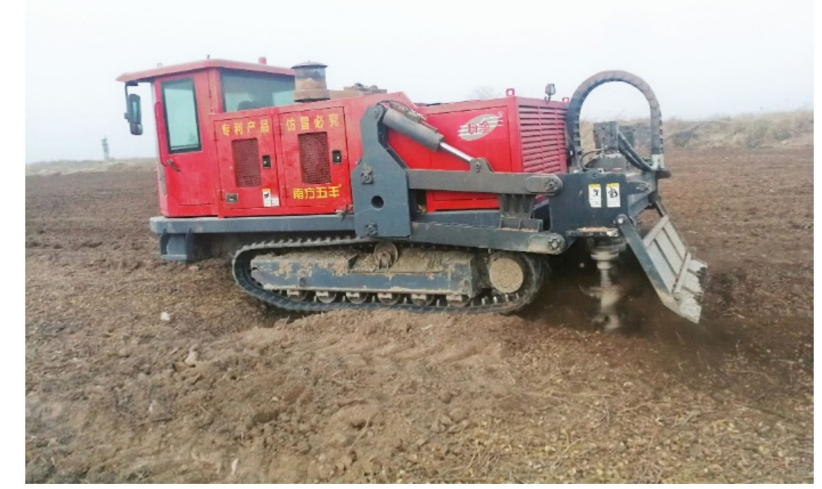

Figure 3. Deep loosener machine for smashing ridge tillage operation.

The studied plant was the Xinluzhong No. 56 cotton variety, which was sown on 4 April 2020, and harvested on 25 September 2020, and sown on 6 April 2021, and harvested on 28 September 2021. A locally promoted planting pattern of "one mulch, three drip pipes, and six crop rows" (Figure $2 \mathrm{~b}$ ) was adopted. The diameter of the drip irrigation belt was $16 \mathrm{~mm}$, the wall thickness was $0.2 \mathrm{~mm}$, the distance between drippers was $30 \mathrm{~cm}$, and the flow rate was $3.2 \mathrm{~L} \mathrm{~h}^{-1}$. The drip irrigation water source was the Yarkand River, which had a salinity of $0.80 \mathrm{~g} \mathrm{~L}^{-1}$ (freshwater salinity $<1.00 \mathrm{~g} \mathrm{~L}^{-1}$ ) and a $\mathrm{pH}$ of 7.38. Irrigation was carried out according to the local conventional irrigation system, and cotton was irrigated 10 times during the whole reproductive period with an interval of about 7-10 d. All plots were irrigated at the same time. The timing of cotton irrigation in 2020 and 2021 is shown in Table 1. Fertilizers were applied in equal amounts according to the "one water, one fertilizer" method, with $472.5 \mathrm{~kg} \mathrm{hm}^{-2}$ of urea (N mass fraction $\geq 46 \%$ ) and $75 \mathrm{~kg} \mathrm{hm}^{-2}$ of agricultural potassium sulfate $\left(\mathrm{K}_{2} \mathrm{O}\right.$ mass fraction $\left.\geq 50 \%\right)$. Other agricultural management measures in the experimental area were the same as those in the surrounding fields. All measurements and treatments remained the same throughout the experiment (2020 and 2021). 
Table 1. Irrigation schedule for 2020 and 2021 growing seasons.

\begin{tabular}{cccccccc}
\hline Year & Date & DAS & $\begin{array}{c}\text { Irrigation } \\
\mathbf{( m m )}\end{array}$ & Year & Date & DAS & $\begin{array}{c}\text { Irrigation } \\
\mathbf{( m m})\end{array}$ \\
\hline \multirow{6}{*}{2020} & June 10 & 67 & 37.5 & & June 12 & 67 & 37.5 \\
& June 21 & 78 & 37.5 & & June 23 & 78 & 37.5 \\
& June 28 & 85 & 37.5 & & June 30 & 85 & 37.5 \\
& July 6 & 93 & 57.5 & & July 8 & 93 & 57.5 \\
& July 13 & 100 & 57.5 & & July 15 & 100 & 57.5 \\
& July 20 & 107 & 57.5 & 2021 & July 22 & 107 & 57.5 \\
& July 27 & 114 & 57.5 & & July 29 & 114 & 57.5 \\
& August 3 & 121 & 57.5 & & August 5 & 121 & 57.5 \\
& August 10 & 128 & 57.5 & & August 12 & 128 & 57.5 \\
& August 25 & 143 & 22.5 & & August 27 & 143 & 22.5 \\
& Total & & 480 & & Total & & 480 \\
\hline DAS:
\end{tabular}

\subsection{Data Collection}

\subsubsection{Soil Bulk Density}

During the cotton harvest period, the cutting-ring method was used to determine the soil bulk density of the $0-60 \mathrm{~cm}$ soil layer, with every $10 \mathrm{~cm}$ as a layer, and sampling was repeated three times for each treatment. Samples were transported to the laboratory in sealed plastic bags, weighed, oven-dried at $105^{\circ} \mathrm{C}$, and reweighed. Bulk density $\left(\mathrm{g} \mathrm{cm}^{-3}\right)$ was determined by dividing the dry soil mass by the sample core volume $\left(100 \mathrm{~cm}^{3}\right)$. The measurement position was in the middle of the wide row of cotton.

\subsubsection{Soil Moisture and EC}

Soil samples were collected using an auger $(5 \mathrm{~cm}$ diameter, $140 \mathrm{~cm}$ height) from each plot at depths of $20 \mathrm{~cm}$ and from 0 to $120 \mathrm{~cm}$ before the irrigation days at different stages of the cotton growth period, which included the seedling stage (20 May 2020 and 22 May 2021), bud stage (20 June 2020 and 22 June 2021), flowering and boll stage (25 July 2020 and 27 July 2021), and boll opening stage (24 August 2020 and 26 August 2021). A total of $20 \mathrm{~g}$ of fresh soil samples was weighed, and the moisture content was measured using the oven drying method $\left(105^{\circ} \mathrm{C}, 24 \mathrm{~h}\right)$. The value of gravimetric water content was the average of three replicates in each treatment.

The soil samples were air-dried and crushed until they could pass through a $2 \mathrm{~mm}$ sieve. Then, the soil electrical conductivity was determined using a conductivity meter (DDS-11A, Shanghai INESA Scientific Instruments Co., Ltd., Shanghai, China) in a mixture of dried soil and distilled water at a ratio of 1:5 (by weight).

\subsubsection{Dry Matter Production}

At the seedling stage, bud stage, flowering and boll stage, and boll opening stage, three cotton samples of uniform growth were selected from each plot, and the above-ground and below-ground parts were collected. After removing the dust on the surface of the obtained fresh plant samples, the organs were separated, put in an oven at $105^{\circ} \mathrm{C}$ for $30 \mathrm{~min}$, and dried at $75^{\circ} \mathrm{C}$ to a constant mass. The samples were weighed with an electronic balance (accurate to $0.01 \mathrm{~g}$ ) to determine their dry weight.

\subsubsection{Cotton Yield}

Three $1 \times 2.4 \mathrm{~m}$ plant samples in each plot were randomly selected, and the yield of seed cotton was weighed. The measured yield constituents were 100-boll weight, plant number, and effective boll number per plant. The yield and its constituents were taken as the average of three plots. 


\subsection{Data Collection}

The data were processed using Microsoft Excel 2019. Analysis of variance was performed using the SPSS 24.0 package (SPSS Inc., Chicago, IL, USA). Tukey's significant difference test was used to determine significant differences between the smashing ridge tillage treatments at $p<0.05$. Origin 2021 software (OriginLab, Northampton, MA, USA) was used to create figures and perform principal component analysis (PCA). The biplots were generated using the first two components (PC1 and PC2), which explained the maximum variation between the data sets.

\section{Results}

\subsection{Soil Bulk Density}

The effects of different smashing ridge tillage depths on the soil bulk density of the 0-60 cm soil layer during cotton harvest are shown in Table 2. The soil bulk density of treatments $\mathrm{A}, \mathrm{B}$, and $\mathrm{C}$ in the $0-20 \mathrm{~cm}$ soil layer was significantly lower than that of CT by $7.40 \%, 8.09 \%, 8.84 \%$, and $6.57 \%, 7.30 \%$, and $8.03 \%$ in 2020 and 2021 , respectively. The soil bulk density of treatment $C$ in the $20-40 \mathrm{~cm}$ soil layer was significantly lower than that of treatments $\mathrm{CT}, \mathrm{A}$, and $\mathrm{B}$, by $8.86 \%, 8.57 \%, 2.29 \%$, and $8.51 \%, 9.15 \%$, and $3.01 \%$ in 2020 and 2021, respectively. The soil bulk density of treatment $C$ in the $40-60 \mathrm{~cm}$ soil layer was significantly lower than the other treatments, decreasing by $11.49 \%$ and $8.90 \%$ in 2020 and 2021, respectively. The differences between CT, A, and B treatments were not significant. On the whole, the soil bulk density of the 0-60 $\mathrm{cm}$ soil layer in treatments A, B, and C decreased by $7.40 \%, 8.09 \%, 8.84 \%$, and $6.57 \%, 7.30 \%$, and $8.03 \%$ in 2020 and 2021 , respectively, compared to $\mathrm{CT}$. The above results showed that the treatment of smashing ridge tillage could reduce the soil bulk density of different soil layers, and the deeper the smashing ridge tillage depth, the greater the bulk density reduction, and the lowest soil bulk density was found in different soil layers of treatment $C$.

Table 2. Changes of soil bulk density at different soil layers under different treatments during cotton harvest.

\begin{tabular}{ccccccc}
\hline \multirow{2}{*}{ Treatments } & \multicolumn{7}{c}{ Soil Depth $(\mathbf{c m})$} \\
\cline { 2 - 7 } & $\mathbf{0 - 2 0}$ & $\mathbf{2 0 - 4 0}$ & $\mathbf{4 0 - 6 0}$ & $\mathbf{0 - 2 0}$ & $\mathbf{2 0 - 4 0}$ & $\mathbf{4 0 - 6 0}$ \\
\cline { 2 - 7 } & $1.36 \pm 0.012 \mathrm{a}$ & $1.42 \pm 0.018 \mathrm{a}$ & $1.48 \pm 0.017 \mathrm{a}$ & $1.37 \pm 0.035 \mathrm{a}$ & $1.41 \pm 0.018 \mathrm{a}$ & $1.46 \pm 0.015 \mathrm{a}$ \\
$\mathrm{nyyyyyy}$ & $1.26 \pm 0.031 \mathrm{~b}$ & $1.40 \pm 0.025 \mathrm{a}$ & $1.47 \pm 0.009 \mathrm{a}$ & $1.28 \pm 0.014 \mathrm{~b}$ & $1.42 \pm 0.014 \mathrm{a}$ & $1.47 \pm 0.033 \mathrm{a}$ \\
A & $1.25 \pm 0.015 \mathrm{~b}$ & $1.31 \pm 0.021 \mathrm{~b}$ & $1.45 \pm 0.006 \mathrm{a}$ & $1.27 \pm 0.032 \mathrm{~b}$ & $1.33 \pm 0.023 \mathrm{~b}$ & $1.46 \pm 0.013 \mathrm{a}$ \\
B & $1.24 \pm 0.022 \mathrm{~b}$ & $1.28 \pm 0.038 \mathrm{c}$ & $1.31 \pm 0.010 \mathrm{~b}$ & $1.26 \pm 0.004 \mathrm{~b}$ & $1.29 \pm 0.026 \mathrm{c}$ & $1.33 \pm 0.020 \mathrm{~b}$ \\
\hline
\end{tabular}

Note: Different letters indicate significant differences between different treatments in the same column $(p<0.05)$. CT, conventional tillage; A, $20 \mathrm{~cm} ; \mathrm{B}, 40 \mathrm{~cm} ; \mathrm{C}, 60 \mathrm{~cm}$.

\subsection{Soil Moisture}

Differences in soil structure in the tillage layer influenced the characteristics of soil moisture changes. The vertical distribution of soil moisture in the different soil layers in 2020 and 2021 for each treatment is shown in Figure 4. The distribution of roots at the measuring depths in the cotton root zone is very different, and therefore the ability to absorb water is also somewhat different. Under the conditions of mulched drip irrigation, more than $85 \%$ of the cotton roots are concentrated in the $0-40 \mathrm{~cm}$ soil layer [31]. Therefore, in this study, the $0-120 \mathrm{~cm}$ soil layer was divided into two regions, $0-40$ and $40-120 \mathrm{~cm}$, to analyze soil moisture during the entire growth period of cotton. At the seedling stage, soil moisture in $0-40 \mathrm{~cm}$ soil layer treatments $\mathrm{A}, \mathrm{B}$, and $\mathrm{C}$ was significantly higher than CT by $8.05 \%, 16.29 \%, 16.73 \%$, and $6.79 \%, 12.07 \%$, and $16.39 \%$ in 2020 and 2021 , respectively, while soil moisture in the 40-120 cm soil layer was lower than CT. At the bud stage, soil moisture in 0-40 cm soil layer treatments A, B, and C was significantly higher than that of CT, and the differences among treatments were small, but the soil moisture in 40-120 cm soil layer treatments B and C was significantly lower than that of CT. Soil evaporation and plant 
transpiration were further enhanced during the flowering bell stage, which was also the peak of water consumption, and water demand increased significantly. The soil moisture in 0-40 cm soil layer treatments A, B, and C was significantly lower than that of CT, and the soil moisture of each treatment in the $40-120 \mathrm{~cm}$ soil layer also showed a significantly lower trend than CT. Overall, soil moisture was lower in treatments A, B, and C than in CT in the $0-120 \mathrm{~cm}$ soil layer at the flowering and boll stage by $7.40 \%, 8.09 \%, 8.84 \%$, and $6.57 \%$, $7.30 \%$, and $8.03 \%$ in 2020 and 2021, respectively. Cotton growth during the boll opening stage had weaker water demand. Soil moisture in treatments B and C in the $0-40 \mathrm{~cm}$ soil layer was still lower than CT, and soil moisture in treatments B and C in the $40-120 \mathrm{~cm}$ soil layer increased slightly compared to CT.

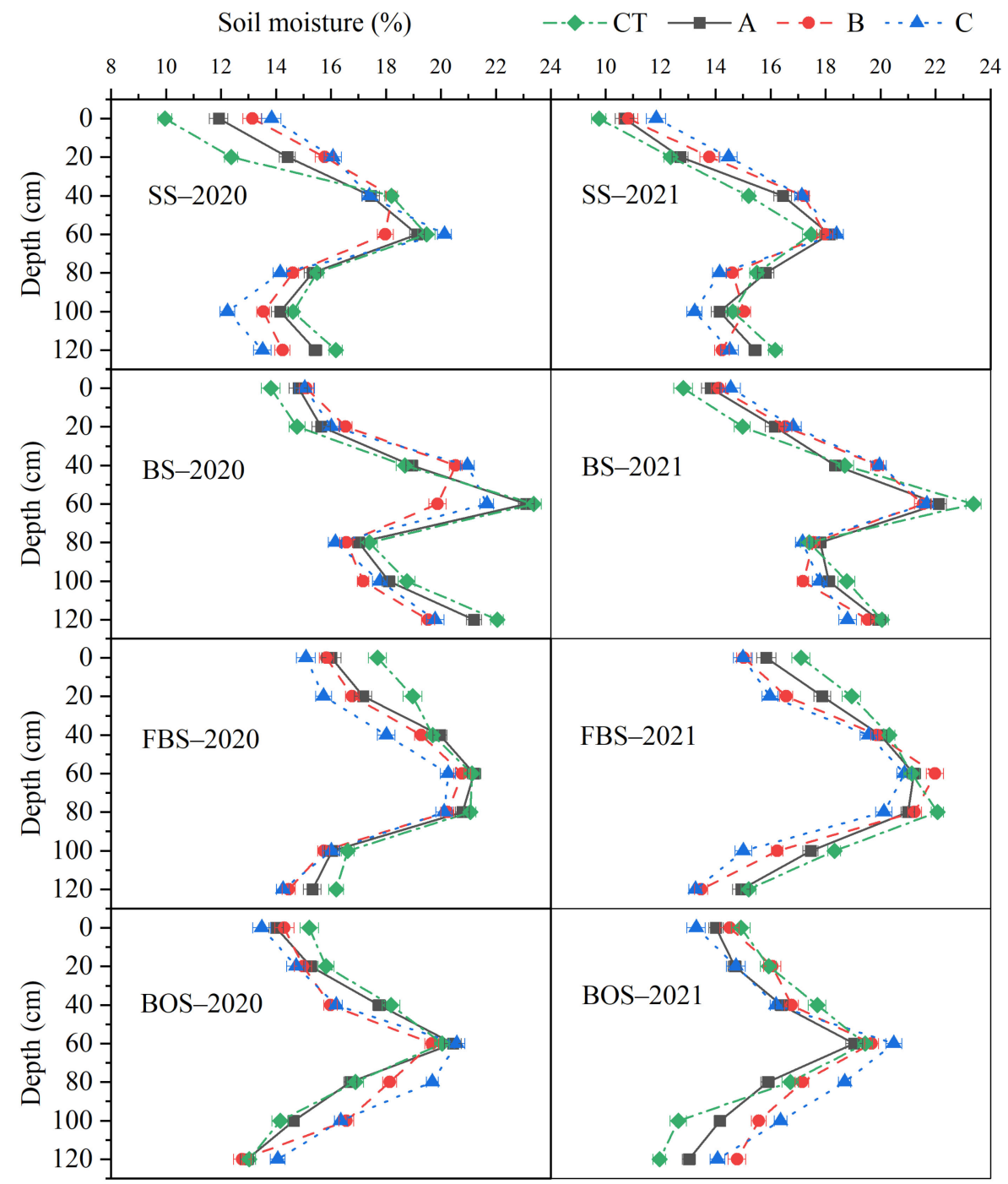

Figure 4. Comparison of the vertical distribution of soil moisture under different smashing ridge tillage depth treatments during the growth periods in 2020 and 2021. Data (mean \pm SD) were collected from soil depths between 0 and $120 \mathrm{~cm}$. CT, conventional tillage; A, $20 \mathrm{~cm}$; B, $40 \mathrm{~cm}$; , $60 \mathrm{~cm}$. SS, seedling stage; BS, bud stage; FBS, flowering and boll stage; BOS, boll opening stage.

\subsection{Soil EC}

Figure 5 shows the distribution of soil EC at different soil depths. In terms of temporal changes in soil salinity, the soil salinity in the $0-120 \mathrm{~cm}$ soil layer of three mashing ridge tillage depth treatments showed a decreasing trend for two consecutive years. At the seedling stage, soil salinity was significantly lower in treatments A, B, and C than in CT in the $0-120 \mathrm{~cm}$ soil layer, by $2.44 \%, 14.07 \%, 24.08 \%$, and $6.88 \%, 31.22 \%$, and $53.20 \%$ in 2020 
and 2021, respectively. At the bud stage, soil salinity was significantly lower in 2020 and 2021 in 0-40 cm soil layer treatments A, B, and C than in CT. In the 40-120 cm soil layer, the soil salinity of treatments A, B, and C in 2020 was significantly increased by $6.88 \%, 31.22 \%$, and $53.20 \%$ compared with CT, respectively. In 2021, there was no significant difference in soil salinity among the treatments. Flowering and boll stage was the peak period of irrigation. The soil salinity of the $0-40 \mathrm{~cm}$ soil layer treatments A, B, and C was significantly lower than that of CT. In general, soil salinity was lower in treatments $\mathrm{A}, \mathrm{B}$, and C than in $\mathrm{CT}$ in the $0-120 \mathrm{~cm}$ soil layer at the flowering and boll stage, by $5.76 \%, 5.86 \%, 14.79 \%$, and $5.38 \%, 17.55 \%$, and $36.67 \%$ in 2020 and 2021 , respectively. At the boll opening stage, soil salinity was reduced by $4.21 \%, 6.75 \%, 11.95 \%$, and $5.47 \%, 24.25 \%$, and $54.13 \%$ in treatments A, B, and C compared to CT in the $0-120 \mathrm{~cm}$ soil layer in 2020 and 2021, respectively. The soil salinity of the $0-120 \mathrm{~cm}$ soil layer in 2021 was significantly lower than that in 2020 , indicating that smashing ridge tillage could significantly reduce soil salinity.

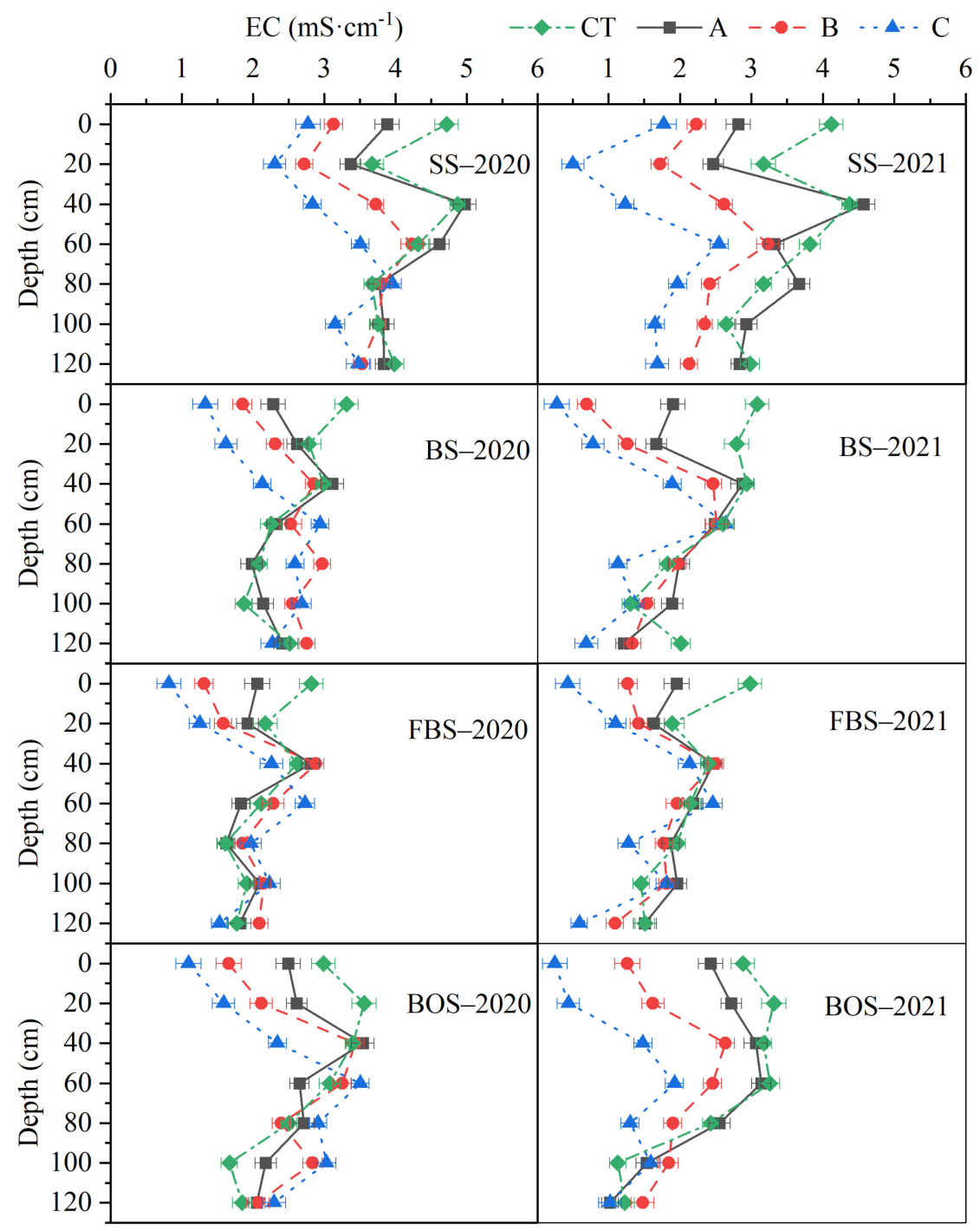

Figure 5. Comparison of soil salinity levels under different smashing ridge tillage depth treatments during the growth periods in 2020 and 2021. Data (mean \pm SD) were collected from soil depths between 0 and $120 \mathrm{~cm}$. CT, conventional tillage; A, $20 \mathrm{~cm} ; \mathrm{B}, 40 \mathrm{~cm} ; \mathrm{C}, 60 \mathrm{~cm}$. SS, seedling stage; BS, bud stage; FBS, flowering and boll stage; BOS, boll opening stage. 


\subsection{Dry Matter Production}

The effect of smashing ridge tillage depth on the dry matter production of cotton is shown in Figure 6. Smashing ridge tillage significantly increased the production of cotton dry matter. Dry matter production at the seedling stage was significantly increased in treatment $\mathrm{C}$ compared to treatments $\mathrm{B}, \mathrm{A}$, and $\mathrm{CT}$. The dry matter production of treatment $C$ at the bud stage in 2020 and 2021 was significantly increased by $12.04 \%$ and $13.07 \%$ compared to $\mathrm{CT}$, respectively. The dry matter production during the flowering and boll stage has the fastest growth rate during the whole growth period. In 2020 and 2021, the increase in the dry matter during the flowering and boll stage accounted for $60.18-61.78 \%$ and $58.36-60.75 \%$ of the total dry matter production, respectively. In 2020 and 2021, the dry matter production of treatment $C$ during the flowering and boll stage and the boll opening stage was significantly higher than that of other treatments. In 2020 and 2021, the dry matter production of treatment $C$ during the boll opening stage increased significantly by $17.16 \%$ and $15.91 \%$ compared with CT. The dry matter production of cotton in each growth period increased with the increase in the smashing ridge tillage depth, and the trend of the dry matter production was $\mathrm{C}>\mathrm{B}>\mathrm{A}>\mathrm{CT}$.
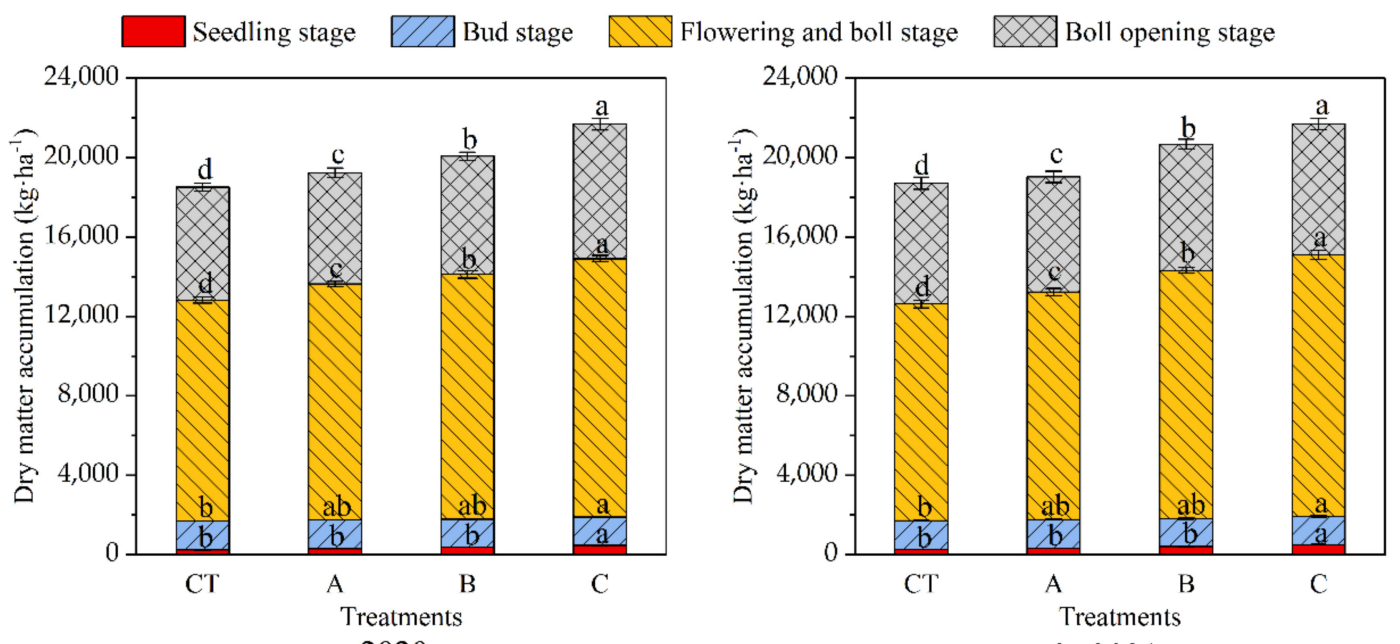

a. 2020

b. 2021

Figure 6. Effects of different smashing ridge tillage depth treatments on dry matter production of cotton in (a) 2020 and (b) 2021. Different lowercase letters represent significant differences ( $p<0.05, t$-test) between treatments per year. CT, conventional tillage; A, $20 \mathrm{~cm} ; \mathrm{B}, 40 \mathrm{~cm} ; \mathrm{C}, 60 \mathrm{~cm}$.

\subsection{Cotton Yield}

Cotton yield, 100-boll weight, and effective bolls increased significantly with the increasing depth of smashing ridge tillage (Figure 7). The 100-boll weight in treatments $B$ and $C$ was significantly higher than in other treatments, and there was no significant difference between treatment A and CT. Treatment $C$ had the highest 100-bell weight with a $4.64 \%$ and $4.68 \%$ increase in 2020 and 2021, respectively, compared with CT. The effective bolls in treatments A, B, and C were significantly higher than CT. Among them, the effective bolls in treatment $\mathrm{C}$ were significantly higher than in other treatments, which increased by $49.79 \%$ and $48.74 \%$ compared with CT in 2020 and 2021, respectively. Treatment A, B, and $C$ cotton yields were significantly higher than $C T$, with treatment $C$ cotton yielding significantly higher than in the other treatments. The highest yields were 4518.75 and $5119.35 \mathrm{~kg} \mathrm{hm}^{-2}$ in 2020 and 2021, respectively, which increased by $65.24 \%$ and $84.14 \%$ compared with CT. The results indicated that the deeper the smashing ridge tillage depth, the better for improving crop yield, which was consistent with the expression of soil salinity. 


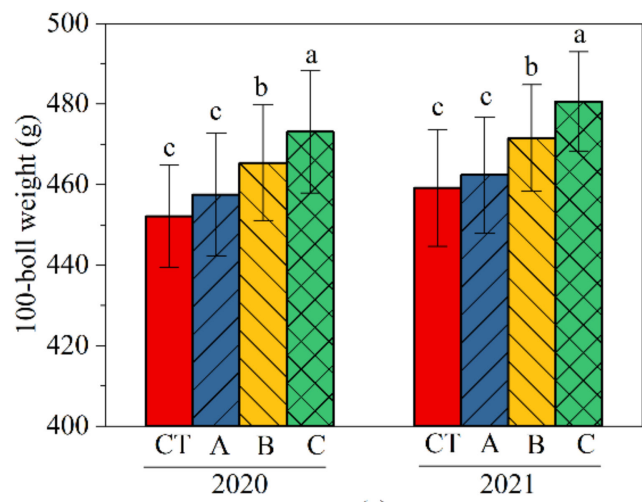

(a)

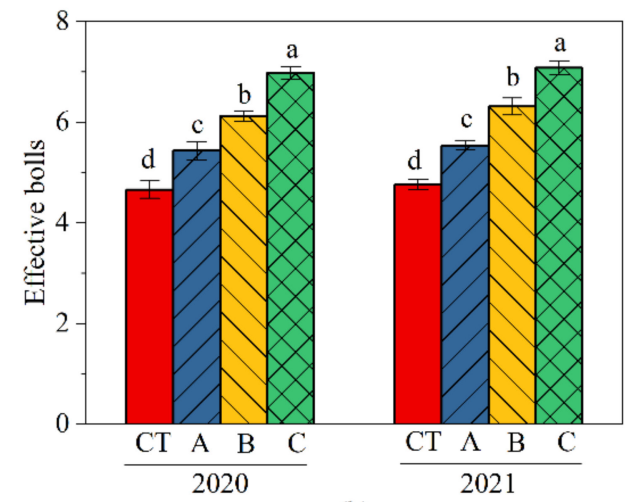

(b)

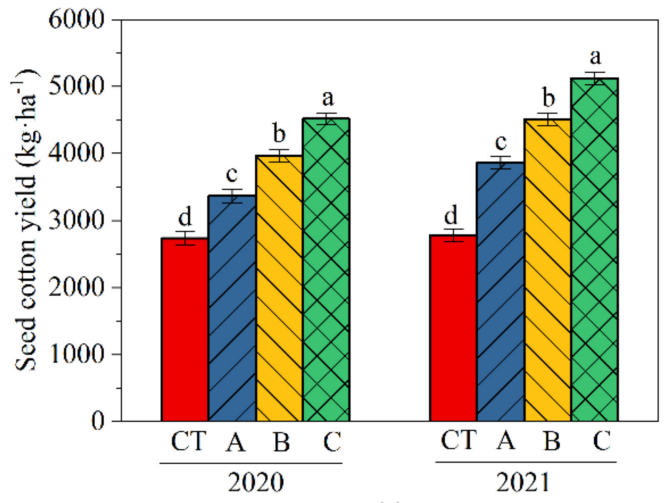

(c)

Figure 7. Effects of different smashing ridge tillage depth treatments on (a) 100-boll weight, (b) effective bolls, and (c) yield of cotton in 2020 and 2021. Different lowercase letters represent significant differences ( $p<0.05$, $t$-test) between treatments per year. CT, conventional tillage; $\mathrm{A}, 20 \mathrm{~cm} ; \mathrm{B}, 40 \mathrm{~cm}$; C, $60 \mathrm{~cm}$.

\subsection{Assessment of Treatment-Variable Interaction through PCA}

To comprehensively evaluate the relationship between different smashing ridge tillage depth treatments for soil bulk density, moisture, salinity, cotton dry matter production, and yield, data obtained for individual treatments were averaged and subjected to PCA (Figure 8). In 2020 and 2021, PC1 and PC2 showed $96.06 \%$ and $94.14 \%$ data variability, respectively. Results of PCA confirmed that soil bulk density, moisture, salinity, cotton dry matter production, and yield were closely associated with treatments $C$ and $B$ and less associated with treatments A and CT. Soil bulk density and salinity were highly significant and negatively associated with cotton dry matter production and yield. These results indicated that a greater depth of smashing ridge tillage could promote water uptake and utilization in cotton to promote root growth and thus increase yield. 

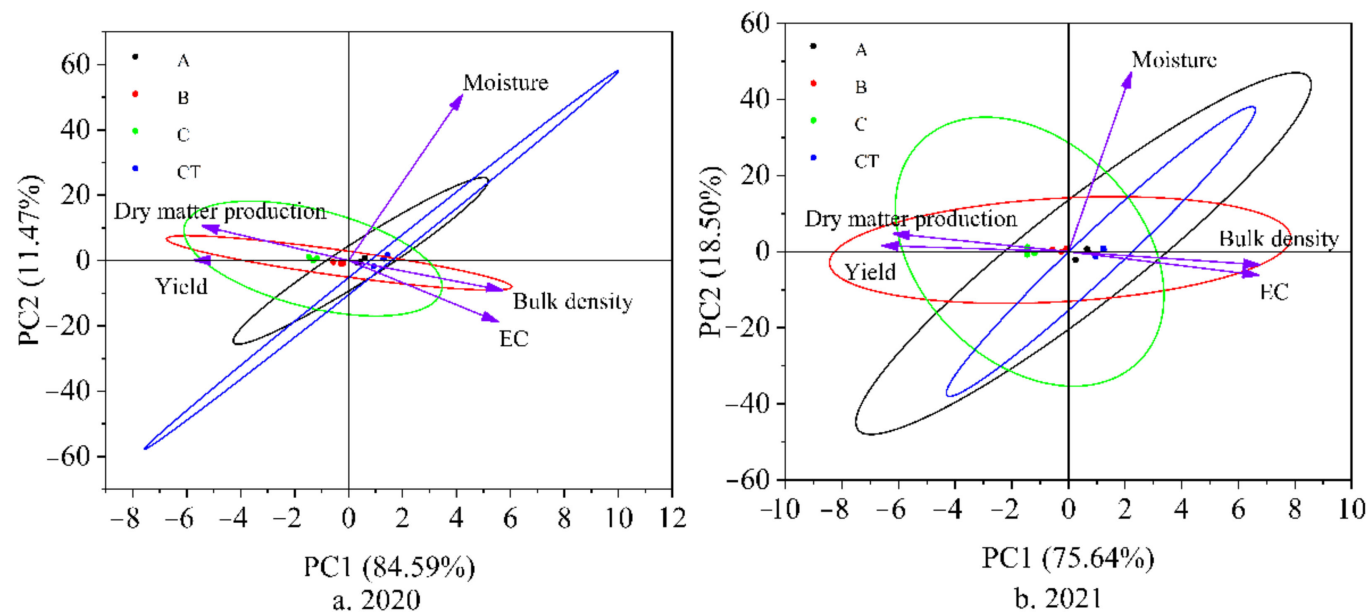

Figure 8. Principal component analysis (PCA) to elucidate the treatment-variable relationships between soil parameters and cotton yield under different smashing ridge tillage depth conditions in (a) 2020 and (b) 2021. The lines originating from the central point of the biplots show negative or positive correlations of different variables, and their closeness indicates strength of correlation with a particular treatment. CT, conventional tillage; A, $20 \mathrm{~cm} ; \mathrm{B}, 40 \mathrm{~cm} ; \mathrm{C}, 60 \mathrm{~cm}$.

\section{Discussion}

\subsection{Effect of Smashing Ridge Tillage on Soil Bulk Density and Moisture}

The impact of tillage measures on soil properties is first manifested in the change of soil bulk density [32]. Smashing ridge tillage can loosen the soil and reduce the soil bulk density compared to traditional rotary tillage, thus increasing soil permeability and water retention [33,34]. Wei et al. [35] found that the soil bulk density after smashing ridge tillage was still lower than traditional tillage after years of continuous planting by $10.56 \%$. The results of this study are consistent with the above findings. The soil bulk density of the 0-60 $\mathrm{cm}$ soil layer after smashing ridge tillage was less than that of traditional tillage treatment, and the increase in the smashing ridge tillage depth had a greater impact on the deep soil bulk density. The average decrease in 2020 and 2021 could reach $4.34 \%$. This may be because smashing ridge tillage can break the bottom of the plow, loosen the plow layer after plowing, improve the soil structure, and reduce the soil bulk density. After smashing ridge tillage, the soil bulk density of each soil layer increased in 2021 compared with 2020, which may be caused by, for example, irrigation and natural soil settlement. The level of soil water content reflects the level of water holding capacity and water supply capacity of the soil $[36,37]$. Smashing ridge tillage can effectively improve soil moisture content. $\mathrm{Li}$ et al. [38] found that powder ridge cultivation breaks the bottom of the soil plow, which is conducive to rainfall infiltration and soil moisture storage. Sun et al. [24] found that by measuring the soil moisture in the $0-60 \mathrm{~cm}$ soil layer of a cotton field with mulched drip irrigation, smashing ridge tillage can significantly increase soil moisture compared with traditional tillage. However, the results of this study were different. Compared with traditional tillage, the smashing ridge tillage increased the soil moisture in the $0-40 \mathrm{~cm}$ soil layer at the seedling stage and bud stage and decreased the soil moisture in the $0-120 \mathrm{~cm}$ soil layer at the flowering and boll stage. This is generally consistent with the research results of Zhai et al. [39]. The reason for this may be that during the growth stage when the water demand is small, the smashing ridge tillage increases soil moisture in the tillage layer, which plays a role in water storage and moisture retention and is beneficial to the growth and development of cotton. As the growth period of cotton progresses, the intensity of water consumption by cotton at the flowering and boll stage increases. Smashing ridge tillage loosens the soil, thickens the tillage layer, increases the rate of water infiltration, promotes root growth and development, and facilitates the vertical distribution of crop roots downward. With the strengthening of transpiration, the supply and consumption 
capacity of deep soil water is enhanced [10]. Deep soil water depletion was increased in the smashing ridge tillage treatment.

\subsection{Effect of Smashing Ridge Tillage on Soil Salinity}

The movement of salt in saline-alkali soil is characterized by the migration of salts along with water [40]. The vertical upward and horizontal movement of water relies mainly on the capillary action of the soil. Smashing ridge tillage uses a spiral drill to cut the soil horizontally so that the soil in the cultivated layer is finely broken, and the internal structure of the soil capillary is reconstructed. By increasing the diameter of the soil capillary and the roughness of the inner wall, the capillary action of the soil is weakened, and the salt in the lower layer is prevented from moving upward [41]. The use of effective physical measures for improving saline soils in smashing ridge tillage follows precisely the law of salt transport in saline soils. Wei et al. [18] found that heavy saline land after smashing ridge tillage showed a $31.31 \%$ decrease in total soil salinity, a $48.80 \%$ increase in cotton yield, and a decrease in salinity from heavy to moderate. The results of this study are consistent with the above reports. The results of this experiment showed that soil salinity was significantly lower in the $0-120 \mathrm{~cm}$ soil layer in different smashing ridge tillage depth treatments at the seedling stage than in traditional tillage, with the most significant decrease in soil salinity in treatment $C$. The possible explanations were that increasing the smashing ridge tillage depth breaks the plow bottom, improves soil porosity, and rebuilds the internal structure of the soil capillary. In addition, the mulching film inhibits evaporation and effectively reduces the upward movement of salinity. With the increase in irrigation frequency during the growth period, the soil salinity in the $0-120 \mathrm{~cm}$ soil layer of different smashing ridge tillage depth treatments was significantly reduced compared with traditional tillage at the flowering and boll stage and boll opening stage. The soil salinity of treatment $C$ was significantly lower than that of other treatments. During irrigation, the salts in the soil of the tillage layer will gradually leach down with the water due to the effect of gravity. The salts are gradually leached to the lower layers with the water and keep moving to deeper layers. Smashing ridge tillage reduces the upward movement of salt in the lower soil and reduces the salt content of the soil in the cultivated layer [20].

\subsection{Effect of Smashing Ridge Tillage on Cotton Growth and Yield}

Soil compaction is the main reason for reducing root vigor and inhibiting root growth [42]. Smashing ridge tillage has both deep loosening and deep plowing characteristics, which can break the bottom of the plow, loosen the soil, and optimize the soil structure. It can also have a significant improvement in the growing environment of crops [43,44], increasing the ability of crop roots to supply water and nutrients by absorption and promoting crop yield growth [45]. Jin et al. [46] found that smashing ridge tillage enhanced the growth and development of potato roots and effectively promoted the development and dry matter accumulation of potato leaves and stems. Liu et al. [47] showed that the effect of smashing ridge tillage cultivation technology on cassava yield increase was significant, with a $46.69 \%$ yield increase compared to the traditional tillage planting method. The findings of this study indicated that increasing the depth of smashing ridge tillage could effectively promote cotton yield improvement. The 100-boll weight, effective bolls, and yield of cotton increased significantly with the increase in the depth of the smashing ridge tillage. Compared with traditional farming, treatment $\mathrm{C}$ increased the cotton yield by $76.21 \%$ and $70.36 \%$ in 2020 and 2021 , respectively. The findings of our study are similar to those of Zhang et al. [48]. The main reason is that the smashing ridge tillage improves the loose conditions of the cotton field tillage layer, which facilitates the deep rooting and the mobilization of water and fertilizer and improves the sustainable supply capacity of water and fertilizer required for cotton growth, thus producing a good effect on cotton development and yield increase. Accordingly, the PCA displayed that the application of the smashing ridge tillage was closely associated with soil bulk density, moisture, salinity, cotton dry matter production, and yield. The PCA results for both years 
were generally consistent, showing a highly significant negative correlation between soil bulk and salinity and cotton dry matter production and yield.

In this study, we concluded that the positive regulating effect of the smashing ridge tillage depth on soil bulk density, water and salt environment, and cotton yield was linear. The optimum indexes were found at a smashing ridge tillage depth of $60 \mathrm{~cm}$. This is the suitable smashing ridge tillage depth for salinized cotton fields in South Xinjiang under the conditions of this experiment. However, for different levels of saline land, when environmental factors such as soil, climate, and crop type change, whether the response of soil/water and soil environment as well as crop production potential to the depth of smashing ridge tillage changes currently needs further research. Like subsoiling and plowing operations, smashing ridge tillage has certain after-effects. It is not necessary to implement the operation every year, and it can be carried out alternately with farming measures such as rotary tillage or no-tillage, and the number of years its effectiveness can be maintained is something that still needs to be further studied.

\section{Conclusions}

In arid regions, the use of limited water resources for saline land improvement to improve the sustainability of agriculture is an urgent issue to be addressed. In this study, the effects of different smashing ridge tillage depth treatments on soil bulk density, water and salt content, dry matter production, and yield were investigated. Based on the two-year field experiment results in 2020 and 2021, our main conclusions are as follows: The increase in the depth of the smashing ridge tillage can significantly reduce soil bulk density and soil salinity, and increase soil moisture, play a role in water storage and moisture preservation and facilitate the absorption and utilization of deep soil moisture by cotton. In addition, the increase in the depth of the smashing ridge tillage promoted the production of dry matter and yield of cotton compared to the traditional tillage. The recommended depth of smashing ridge tillage for the improvement of salinized cotton fields and sustainable agricultural production in South Xinjiang is $60 \mathrm{~cm}$.

Author Contributions: Conceptualization, Z.B., T.W. and H.L. (Hongguang Liu); methodology, H.L. (Hongguang Liu); software, Z.B.; validation, P.G., H.L. (Huiqin Li) and L.L.; formal analysis, H.L. (Hongguang Liu); investigation, Z.B.; resources, H.L. (Hongguang Liu); data curation, Z.B.; writing—original draft preparation, Z.B.; writing—review and editing, B.X., Y.X.; visualization, Z.B.; supervision, M.C., J.F.; project administration, H.L. (Hongguang Liu) and T.W.; funding acquisition, H.L. (Hongguang Liu) and T.W. All authors have read and agreed to the published version of the manuscript.

Funding: This research was jointly supported by the National Natural Science Foundation of China (No. 52069026, U1803244), Xinjiang Production and Construction Corps (No. 2020DB001, 2021BC003) and Third Division of Xinjiang Production and Construction Corps (No. KY2021GG11).

Institutional Review Board Statement: Not applicable.

Informed Consent Statement: Not applicable.

Data Availability Statement: Not applicable.

Conflicts of Interest: The authors declare no conflict of interest.

\section{References}

1. Yang, G.; Li, F.D.; Tian, L.J.; He, X.L.; Gao, Y.L.; Wang, Z.L.; Ren, F.T. Soil physicochemical properties and cotton (Gossypium hirsutum L.) yield under brackish water mulched drip irrigation. Soil Till Res. 2020, 199, 104592. [CrossRef]

2. He, P.R.; Zhang, F.C.; Hou, X.H.; Liu, L.J.; Meng, X.C.; Zhang, C.Y.; Cheng, H.L. Effects of soil water regulation on cotton yield and soil water salt distribution under drip irrigation in southern Xinjiang. Res. Soil Water Conserv. 2020, 27, 84-92. [CrossRef]

3. Xin, M.H.; Wang, Z.B.; Li, X.F.; Han, Y.C.; Feng, L.; Whang, G.P.; Lei, Y.P.; Yang, B.F.; Xiong, S.W.; Fang, Z.Y.; et al. Study on suitable planting density of cotton under machine-picked planting mode in South Xinjiang. Shandong Agric. Sci. 2020, 52, 46-52. [CrossRef]

4. Xu, F.P.; Li, Y.K.; Ren, S.M. Investigation and discussion of drip irrigation under mulch in Xinjiang Uygur Autonomous Region. Trans. Chin. Soc. Agric. Eng. 2003, 1, 25-27. [CrossRef] 
5. Wang, H.M.; Liu, X.H. Problems and countermeasures of efficient water-saving irrigation in southern Xinjiang. Water Resour. Plan. Des. 2018, 10, 72-74. [CrossRef]

6. Tang, C.Y.; Mai, W.X.; Zhao, Z.Y. Study on key technologies of ecological management of saline alkali land in arid area of Xinjiang. Acta Ecol. Sin. 2016, 36, 7064-7068. [CrossRef]

7. Wang, J.L.; Huang, X.J.; Zhong, T.Y.; Chen, Z.G. Review on sustainable utilization of salt-affected land. Acta Geogr. Sin. 2011, 66, 673-684.

8. Mu, H.C.; Hudan, T.; Su, L.T.; Mahemujiang, A.; Wang, Y.M.; Zhang, J.Z. Salt transfer law for cotton field with drip irrigation under mulch in arid region. Trans. Chin. Soc. Agric. Eng. 2011, 27, 18-22. [CrossRef]

9. Yang, P.N.; Dong, X.G.; Liu, L.; Yang, X.X.; Zhang, Y.Y. Soil salt movement and regulation of drip irrigation under plastic film in arid area. Trans. Chin. Soc. Agric. Eng. 2011, 27, 90-95. [CrossRef]

10. Wang, L.; Guo, R.S.; Wumaierjiang, K.; Tian, L.W.; Lin, T.; Zheng, Z.P.; Xu, H.J.; Kong, F.Y.; Cui, J.P. Effects of subsoiling depth on water use efficiency and yield of cotton field under drip irrigation in south Xinjiang, China. Trans. Chin. Soc. Agric. Eng. 2020, 36, 144-152. [CrossRef]

11. Bai, W.; Sun, Z.X.; Zheng, J.M.; Liu, Y.; Hou, Z.Y.; Feng, L.S.; Qian, C.; Yang, N.; Chen, F.; Zhe, Z. The combination of subsoil and the incorporation of corn stover affect physicochemical properties of soil and corn yield in semi-arid China. Toxicol. Environ. Chem. 2016, 98, 561-570. [CrossRef]

12. Kalinichenko, V.; Sharshak, V.; Bezuglova, O.; Ladan, E.; Genev, E.; Illarionov, V.; Zinchenko, V.; Morkovskoi, N.; Chernenko, V.; Il'ina, L. Changes in the soils of solonetzic associations in 30 years after their reclamation with the use of moldboard plowing, deep tillage with a three-tier plow, and deep rotary tillage. Eurasian Soil Sci. 2011, 44, 927-938. [CrossRef]

13. Shao, Y.H.; Xie, Y.X.; Wang, C.Y.; Yue, J.Q.; Yao, Y.Q.; Li, X.D.; Liu, W.X.; Zhu, Y.J.; Guo, T.C. Effects of different soil conservation tillage approaches on soil nutrients, water use and wheat-maize yield in rainfed dry-land regions of North China. Eur. J. Agron. 2016, 81, 37-45. [CrossRef]

14. Hou, X.Q.; Li, R.; Jia, Z.K.; Han, Q.F.; Wang, W.; Yang, B.P. Effects of rotational tillage practices on soil properties: Winter wheat yields and water-use efficiency in semi-arid areas of north-west China. Field Crops Res. 2012, 129, 7-13. [CrossRef]

15. Dec, D.; Dörner, J.; Becker-Fazekas, O.; Horn, R. Effect of bulk density on hydraulic properties of homogenized and structured soils. R. C. Suelo Nutr. Veg. 2008, 8, 1-13. [CrossRef]

16. Laker, M. Soil compaction: Effects and amelioration. Proc. S. Afr. Sug. Technol. Ass. 2001, 75, 125-128.

17. Alcántara, V.; Don, A.; Well, R.; Nieder, R. Deep ploughing increases agricultural soil organic matter stocks. Glob. Change Biol. 2016, 22, 2939-2956. [CrossRef]

18. Wei, B.H.; Shen, Z.Y.; Zhou, J.; Gan, X.Q.; Lao, C.Y.; Zhou, L.Z.; Liu, B.; Hu, P.; Li, Y.Y. Initial exploration on effect of saline-alkali land rebuilding and utilization by fenlong cultivation. J. Agric. Sci. Technol. 2017, 19, 107-112. [CrossRef]

19. Tang, M.Y.; Wang, Q.; Chen, L.; Zhang, X.L.; Zhang, Z.Q.; Lv, R.H.; Liang, T.F. On the growth and physiological characteristics of rice under smashing ridge tillage. Agric. Sci. Technol. 2016, 17, 334. [CrossRef]

20. Lyu, J.F.; Wei, B.H.; Hou, H.Z.; Zhang, G.P. Effect of smashridging cultivation in rainfed agriculture. Gansu Agric. Sci. Tech. 2013, 10, 43-44. [CrossRef]

21. Wei, B.H. Yield Increasing and quality improving effects of smash-ridging method (" 4453 " effects) and its potential in benefiting the nation and the people. Agric. Sci. Technol. 2014, 15, 1767-1769. [CrossRef]

22. Wei, B.H.; Gan, X.Q.; Chen, B.S.; Shen, Z.Y.; Yu, J.; Ning, X.C.; Lu, L.Y.; Wei, G.P.; Hu, P.; Mo, R.X. Comparison of the cultivation of maize and peanuts by smash-riding and traditional land preparation methods. J. Anhui Agric. Sci. 2011, 39, 3216-3219. [CrossRef]

23. Gan, X.Q.; Wei, B.H.; Shen, Z.Y.; Lu, L.Y.; Hu, P.; Wu, Y.Y.; Li, Y.Y.; Mo, R.X. Roots, plants and yield of mulberry by smash-ridging cultivation. J. Zhejiang Agric. Sci. 2011, 3, 705-707. [CrossRef]

24. Sun, M.L.; Lin, G.C.; Hui, J.T.; Xian, H.; Ren, X.R.; Zhang, R.L.; Yang, J. Effects of smash-ridging cultivation on physical and chemical properties of saline-alkali soil and cotton growth in Xinjiang. China Soils Fert. 2020, 6, 58-64. [CrossRef]

25. Hasigerile; Qu, Z.Y.; Wang, F. Water-heat-salt effects of applying desulphurization gypsum and biochar on saline-alkali soil under smashing ridge tillage. Water Sav. Irrig. 2019, 9, 19-22. [CrossRef]

26. Nie, S.W.; Zhang, Y.T.; Tang, F.S.; Zhang, Q.P.; He, N.; Guo, Q.; Wang, H.Q.; Wei, B.H. Effects of later effect of smashing ridge tillage on summer maize's micro environment. J. Shanxi Agric. Sci. 2016, 44, 348-352. [CrossRef]

27. Gan, X.Q.; Wei, B.H.; Liu, B.; Shen, Z.Y.; Lao, C.W.; Li, Y.Y.; Hu, P.; Wu, Y.Y. Effects of smash-ridging cultivation on soil properties, yield and quality of the sixth season of rice. J. South. Agric. 2014, 45, 1603-1607. [CrossRef]

28. Wei, B.H. Reconstruction of highly-efficient smash-ridging ecological cultivation method for sustainable yield-increasing of soil plough layers. Agric. Sci. Technol. 2014, 15, 1526-1529. [CrossRef]

29. Nie, S.W.; Zhang, Y.T.; Zhang, Q.P.; Guo, Q.; Tang, F.S.; Wang, H.Q.; He, N. Effect of smashing ridge tillage on grain yields of winter wheat and summer maize and contents of soil nutrients. Chin. J. Soil Sci. 2017, 48, 930-936. [CrossRef]

30. Nie, S.W.; Zhang, Y.T.; Tang, F.S.; Zhang, Q.P.; He, N.; Wei, B.H. Later-effect of smashing ridge tillage on summer maize's growth and grain yields in fluvo-aquic soil farmlands. J. Shanxi Agric. Sci. 2015, 43, 837-839. [CrossRef]

31. Cui, Y.S.; Wang, F.; Sun, J.S.; Han, Q.S.; Wang, J.L.; Li, N. Efects of irigation regimes on the variation of soil water and salt and yield of mechanically harvested cotton in Southern Xinjiang, China. Chin. J. Appl. Ecol. 2018, 29, 3634-3642. [CrossRef]

32. Abu-Hamdeh, N.H. Compaction and subsoiling effects on corn growth and soil bulk density. Soil Sci. Soc. Am. J. 2003, 67, 1213-1219. [CrossRef] 
33. Wei, B.H.; He, H.Y.; Yu, J.; Gan, X.Q.; Ning, X.C.; Lu, L.Y.; Tang, X.H.; Wei, G.P. Effects of different soil farming ecological types in dry land on cassava growth and environment. J. Anhui Agric. Sci. 2010, 38, 668-671. [CrossRef]

34. Zhang, Y.L.; Zhang, Y.L.; Huang, Y.; Zou, H.T.; Xin, D.X.; Zhang, Z.Y. Effect of deep loosening cultivation on soil nutrients and corn yield in semiarid region of Western Liaoning Province. Agric. Res. Arid Areas 2009, 27, 167-170.

35. Wei, B.H.; Gan, X.Q.; Li, Y.Y.; Shen, Z.Y.; Zhou, L.Z.; Zhou, J.; Liu, B.; Lao, C.W.; Hu, P. Effects of once fenlong cultivation on soil properties and rice yield and quality for 7 consecutive years. Agric. Sci. Technol. 2017, 18, 2365-2371. [CrossRef]

36. Li, X.; Yan, H.K.; Cao, M.J.; Wang, J.H.; Li, M.; Yu, H.Q.; Wang, X.G. Effects of different tillage managements on soil moisture and growth and development of maize. J. Maize Sci. 2009, 17, 76-78+81.

37. Pyndak, V.; Loboiko, V.; Pavlenko, V. Deep chiseling of soil under irrigation conditions. Russ. Agric. Sci. 2009, $35,132-133$. [CrossRef]

38. Li, Z.B.; Pang, H.C.; Yang, X.; Li, Y.Y.; Li, H.; Ren, T.Z.; Dong, G.H.; Guo, L.H. Effects of deep vertically rotary tillage on soil water and water use efficiency in northern China's Huang-huai-hai Region. Acta Ecol. Sin. 2013, 33, 7478-7486. [CrossRef]

39. Zhai, Z.; Li, Y.Y.; Guo, J.J.; Wang, J.; Dong, G.H.; Guo, Z.H.; Pang, H.C. Effect of tillage depth on soil physical properties and yield of winter wheat-summer maize. Trans. Chin. Soc. Agric. Eng. 2017, 33, 115-123. [CrossRef]

40. Zhou, B.B.; Hou, Y.L.; Wang, Q.J. Characteristics of water and salt migration in process of improving saline alkali soil with bacillus subtilis. Trans. Chin. Soc. Agric. Eng. 2018, 34, 104-110. [CrossRef]

41. Wei, B.H.; Shen, Z.Y.; Zhou, J.; Zhou, L.Z.; Hu, P.; Zhang, X. Study on Effect and mechanism of improving saline-alkali soil by fenlong tillage. Soils 2020, 52, 699-703. [CrossRef]

42. Zhang, R.F.; Yang, H.S.; Gao, J.L.; Zhang, Y.Q.; Wang, Z.G.; Fan, X.Y.; Bi, W.B. Effect of subsoiling on root morphological and physiological characteristics of spring maize. Trans. Chin. Soc. Agric. Eng. 2015, 31, 78-84. [CrossRef]

43. Meng, F.D.; Ma, L.; Shi, S.B.; Guo, F.; Liu, X.Q.; Zhu, J.; Mao, J.X.; Liu, Z.X. Dynamics change of dry matter accumulation and relative characteristics of spring wheat under different tillage. J. Triticeae Crops 2007, 4, 693-698. [CrossRef]

44. Wang, H.G.; Yu, Z.W.; Zhang, Y.L.; Shi, Y.; Wang, D. Effects of tillage regimes on water consumption and dry matter accumula-tion in dryland wheat. Acta Agron. Sin. 2012, 38, 675-682. [CrossRef]

45. Cai, H.G.; Ma, W.; Zhang, X.Z.; Ping, J.Q.; Yan, X.G.; Liu, J.Z.; Yuan, J.C.; Wang, L.C.; Ren, J. Effect of subsoil tillage depth on nutrient accumulation, root distribution, and grain yield in spring maize. Crop J. 2014, 2, 297-307. [CrossRef]

46. Jin, X.M.; Du, J.; Shen, R.Z.; Shen, Z.R.; Xie, Y.L.; Wang, Y.M.; Wei, B.H. The effection of sumash-ridging cultivation technology on the growth and yield of corn in Yellow River irrigation district of Ningxia. J. Agric. Sci. 2013, 34, 50-53. [CrossRef]

47. Liu, G.W.; Huang, Z.H.; Wei, B.H.; Mo, Z.M.; Rong, L.X. Effects of ridge cultivation technique on the growth and yield of cassava. J. South. Agric. 2011, 42, 975-978. [CrossRef]

48. Zhang, X.C.; Ma, Y.F.; Yu, X.F.; Hou, H.Z.; Wang, H.L.; Fang, Y.J.; Zhang, G.P.; Lei, K.N. Effects of tillage depth on soil hydrological characteristics and potato yield on northwest Loess Plateau. Acta Agron. Sin. 2021, 47, 138-148. [CrossRef] 